\title{
Widening inequalities
}

ir, on 25 February 2020, I was privileged and delighted to attend the Marmot 10-year Review which concluded that health inequalities were widening. They were avoidable and unjust. I left the meeting thinking that we as a society could surely do better. A month later the national lockdown left many children in disadvantaged homes suffering, to an even greater extent. It took the brave action and the kind heart of young footballer, Marcus Rashford to secure a daily free meal for these children during school holidays. The implications of this inequality is complicated and has many ramifications.

In 2010 Camden Primary Care Trust (PCT) introduced the initiative of the 'Child Friendly Practice' to help reduce the high levels of dental decay prevalent in the borough - one of the highest in the country. The initiative was led by Archna Mathur and Lorna Kent of the PCT and Dr Wendy Bellis, Specialist Paediatric Senior Dental Officer. Four practices in Camden were selected of which Arrow Dental Practice was one. The whole practice team received high quality training and support from the PCT and a health visitor. Dr Bellis also visited each practice offering additional personalised training. The initiative's aim was to encourage parents to visit their dentist for an examination upon their children's first tooth eruption.

Health visitors also facilitated the initiative.

Dentists were to offer advice and instruction on oral hygiene, diet and fluoridation. This subsequently resulted in a significant increase in the number of children seen and treated. The Child Friendly Practice initiative ended after only one year due to a lack of funding. Arrow Dental Practice has continued to be child friendly ever since and continues to see and treat children.

In collaboration with the Department of Dental Public Health at UCL, Dr Alex Blokland audited 584 children seen by the practice with an age range of 7 months to 11 years. The findings were astonishing. The gender demographic was $51.7 \%$ male and $48.3 \%$ female. Numbers of decayed and filled teeth (for deciduous and permanent teeth) were recorded during the first and last visit of every child. Treatment was categorised as fillings, pulpotomy/ pulpectomy, extraction and referral. It was also recorded whether the child had been advised on oral hygiene and diet.

More than half of all children (53.2\%) needed and received treatment at the practice. $98 \%$ continued to attend the practice. At their last appointment, 70\% had zero decay in their deciduous teeth and 93.16\% did not have a permanent dentition filling. Only $11 \%$ required referral for secondary care.

\section{'Dentists are exceptionally well adapted to infection control measures and keeping patients safe - it has been drummed into us from the very beginning of our training'}

From the results, it is evident that giving dietary advice and oral hygiene instruction on a regular basis along with early child friendly treatment decreases the risk of decay, extraction and in some cases referral to secondary care. This requires both the patience and time of the practitioner but reduces child anxiety, pain and in some cases the need for extractions under general anaesthetic saving the NHS considerable sums of money. In November 2016, the Royal College of Surgeons of England published results highlighting that tooth extraction remained the number one procedure carried out on children aged 5-9 in hospitals. The analysis of hospital admitted patient care activity showed that there were 24,945 operations to extract teeth on 5-9 year olds. These data also show there were 9,220 tooth extractions performed on 1-4 year olds. ${ }^{1,2}$

Professor Nigel Hunt, Dean of the Faculty of Dental Surgery at The Royal College of Surgeons said, and I quote, 'we should be ashamed of the state of our children's oral health. New figures published today show tooth extraction, which is most commonly needed due to tooth decay, still remains the number one procedure carried out on 5-9 year olds in hospital, with nearly 25,000 tooth extractions in 2015/16'. ${ }^{1}$ Lucy Middleton of Metro cited The Local Government Association said that these extractions cost the NHS just under 40 million pounds a year ${ }^{3}$ on something that can be easily prevented with better oral health education and healthy diet.

COVID-19, the lockdown, parents' concerns about finance and the future has left many children very anxious and undoubtedly their oral health has been neglected. My deep concern is that the current situation we find ourselves in as general practitioners will exacerbate inequality and undo all the hard work and gains of such initiatives. Social distancing, long waiting lists, expensive PPE and the advice to reduce aerosol generating procedures will discourage dentists treating children. This will result in more referrals to secondary care, more extractions under GA and increased, unnecessary child suffering and distress.

A few weeks ago, I had a practice transition monitoring call from the CQC. I was expressing my worry about deteriorating oral health in children and was reminded by the inspector about the vital role dentists have in promoting health in general especially at a time when its increasingly difficult for patients to be seen by their GPs. Dentists are exceptionally well adapted to infection control measures and keeping patients safe it has been drummed into us from the very beginning of our training. We therefore have an opportunity to contribute to the wellbeing of all our patients and particularly children in these difficult times. We need to go back to seeing our patients regularly to promote oral health and health in general. We need to be inspired by the courage and tenacity of Marcus Rashford, to believe we can make a difference. Asil Alsam, London.

\section{References}

1. Royal College of Surgeons of England. New statistics show tooth extraction number on hospital procedure for 5-9 year olds. Available online at: www.rcseng.ac.uk/news-and-events/ media-centre/press-release/news-statistics-ontooth-extraction/ (Accessed November 2020).

2. NHS Digital. Hospital admitted patient care activity. Available online at: https://webarchive. nationalarchives.gov.uk/20180328130140/ http://digital.nhs.uk/catalogue/PUB22378 (Accessed November 2020).

3. Metro News. NHS spent $\mathrm{f} 40$ million removing children's teeth rotted by sugar. Available online at: https://metro.co.uk/2018/12/01/ nhs-spent-40-million-removing-childrensteeth-rotted-by-sugar-8195082/ (Accessed November 2020). 